\title{
5 Research Square

\section{Influence of rs1292037 Genetic Variant on miR-21 Gene Expression in Patients with type 1 Diabetes Mellitus}

\section{Reza Bayat}

University of Guilan Faculty of Basic Sciences

Zivar Salehi ( $\square$ geneticzs@yahoo.co.uk)

University of Guilan

Setila Dalili

Guilan University of Medical Sciences

Farbod Bahreini

Tarbiat Modares University Faculty of Biological Sciences

\section{Primary research}

Keywords: Type 1 diabetes mellitus, microRNAs, Single nucleotide polymorphism, rs1292037

Posted Date: May 20th, 2021

DOl: https://doi.org/10.21203/rs.3.rs-527664/v1

License: (c) (i) This work is licensed under a Creative Commons Attribution 4.0 International License. Read Full License 


\section{Abstract}

\section{Background}

MicroRNAs (miRNAs) are small non-coding RNA molecules that play a pivotal role in the central dogma of molecular biology by regulating gene expression. Alterations in the expression pattern of miRNAs are seen to be linked with several human diseases including autoimmune diseases such as pediatric type 1 diabetes mellitus (T1DM). Single nucleotide polymorphism (SNP) of the miRNAs coding genes can influence pancreatic development and insulin secretion. We contemplated a relation between miR-21 expression level as well as miR-21 rs1292037 SNP and pediatric T1DM.

\section{Results}

The heterozygous T/C genotype was seen to be more common amongst T1DM patients than amongst controls $(\mathrm{OR}=2.74$ (1.78-4.27), $\mathrm{P}<0.0001)$. The $\mathrm{C}$ allele was more frequent in patients than in control subjects $(\mathrm{OR}=1.36(1.03-0.8), \mathrm{P}=0.02) . m i R-21$ expression was seen to be upregulated in patients compared to the controls by more than twofold $(p<0.0001)$. In the study population, miR-21 was found to be significantly upregulated when carrying the $\mathrm{T} / \mathrm{C}$ genotype.

\section{Conclusions}

We report that the miR-21 rs1292037 variant is related to T1DM. Our study also suggests that the miR-21 expression level is upregulated in T1DM patients compared to the control subjects.

\section{1- Background}

Type 1 diabetes mellitus (T1DM) is a multifactorial autoimmune disease with long-lasting and extreme impacts on individuals, their families, and society (1). T1DM occurs with selective loss of pancreatic $\beta$ cells, which leads to insulin deficiency (2). T1DM can severely affect multiple organs including the heart, kidney, and nerves (3). It has been well-documented that genetic factors play a pivotal role in the incidence and pathogenicity of T1DM (4). The epidemiological studies on pediatric T1DM have raised concerns due to the increasing rate of its prevalence in the world (5). It is estimated that $0.3 \%$ of children are diagnosed with T1DM in the United States, annually (6). It has been well-established that early diagnosis of T1DM can significantly prevent T1DM complications and would increase the effectiveness of T1DM treatments including stem cell transplantation and $\beta$ cells regeneration strategies $(7,8)$.

microRNAs (miRNAs) are endogenous, evolutionary conserved single-stranded molecules with about 22 nucleotides; miRNAs act in cell communication via regulating gene expression by base-pairing with different sites of the transcriptome, mainly the $3^{\prime}$ untranslated region (3'UTR) of their target mRNAs (9). Studies have illustrated that miRNAs play a significant role in the development and proper function of $\beta$ cells (10). 
Single-nucleotide polymorphisms (SNPs) are the most common and basic form of genetic mutations, which are well-contemplated, and can induce devastating phenotypic outcomes (11). Studies have vastly reported that SNPs in the miRNAs coding genes can affect the binding affinity and binding ability of the miRNAs and even can alter the target mRNA (12). miRNAs-related SNPs are known to be associated with the incidence of several diseases including T1DM (13). Limited studies have investigated the association between miR-21 rs1292037 SNP and human-related diseases to this date. In a study on cervical cancer patients by Zhang and their colleagues, it is demonstrated that miR-21 rs 1292037 SNP decreases the cumulative survival of patients by almost 30\%. In the same study, miR-21 rs 1292037 was seen to increase the chemoresistance in patients (14). However, no relation was detected between this reference SNP and either breast cancer or ischemic stroke $(15,16)$. Furthermore, alteration in the expression level of miR-21 is reported to be linked with the incidence of T1DM by inhibiting T cells apoptosis, which consequently can induce autoimmunity (17). Considering these data, we speculated that miR-21 rs1292037T > C may be associated with the incidence of pediatric T1DM. To evaluate this speculation, we employed molecular genetic methods in a case-control study.

\section{2- Results}

\section{Features of the Study Subjects}

The study is comprised of 250 T1DM patients and 250 control subjects. The clinical and biochemical characteristics are depicted in Table 1. There were no statically significant differences in age, gender, and body mass unit. Nonetheless, the hemoglobin A1C was significantly higher in T1DM patients compared to the control subjects. The mean age of diagnosis in T1DM patients was observed to be $8.119 \pm 3.69$. Polyuria, polydipsia, and lethargy conditions were detected in $100 \%, 96.8 \%$, and $61.2 \%$, respectively. $93.6 \%$ of patients reported significant weight loss, and $64.4 \%$ of them disclosed abdominal pain. 
Table 1

Clinical and biochemical characteristics of the study population.

\begin{tabular}{|c|c|c|c|}
\hline Variables & $\begin{array}{l}\text { Case } \\
\text { n (\%) }\end{array}$ & $\begin{array}{l}\text { Control } \\
\text { n (\%) }\end{array}$ & P-value \\
\hline Age & $10.26 \pm 3.57$ & $10.81 \pm 3.58$ & 0.11 \\
\hline Gender & $114(45.6 \%)$ & $116(46.4 \%)$ & 0.19 \\
\hline Male & $136(54.4 \%)$ & $134(53.6 \%)$ & 0.07 \\
\hline \multicolumn{4}{|l|}{ Female } \\
\hline $\mathrm{BMI}^{\mathrm{a}}$ & $16.67 \pm 1.61$ & $17.00 \pm 1.60$ & 0.29 \\
\hline Hemoglobin A1C & $9.64 \pm 1.65$ & $5.13 \pm 0.26$ & $<0.0001$ \\
\hline Age of Diagnosis & $8.119 \pm 3.69$ & & \\
\hline Family History of Diabetes & $24(9.6 \%)$ & $3(1.2 \%)$ & $<0.0001$ \\
\hline Type 1 & $137(54.8 \%)$ & $15(6 \%)$ & $<0.0001$ \\
\hline Type 2 & 89 (35.6\%) & $232(92.8 \%)$ & $<0.0001$ \\
\hline \multicolumn{4}{|l|}{ None } \\
\hline Polyuria & $250(100 \%)$ & & \\
\hline Yes & $0(0 \%)$ & & \\
\hline \multicolumn{4}{|l|}{ No } \\
\hline Polydipsia & $242(96.8 \%)$ & & \\
\hline Yes & $8(3.2 \%)$ & & \\
\hline \multicolumn{4}{|l|}{ No } \\
\hline Weight Loss & $234(93.6 \%)$ & & \\
\hline Yes & $16(6.4 \%)$ & & \\
\hline \multicolumn{4}{|l|}{ No } \\
\hline Abdominal Pain & $161(64.4 \%)$ & & \\
\hline Yes & $89(35.6 \%)$ & & \\
\hline No & & & \\
\hline
\end{tabular}

${ }^{\mathrm{a} B M I}=$ Body mass unit 


\begin{tabular}{|lll|}
\hline Variables & $\begin{array}{l}\text { Case } \\
\mathbf{n}(\%)\end{array}$ & $\begin{array}{l}\text { Control } \\
\mathbf{n}(\%)\end{array}$ \\
\hline Lethargy & $153(61.2 \%)$ & \\
Yes & $97(38.8 \%)$ & \\
No & & \\
\hline aBMl= Body mass unit & & \\
\hline
\end{tabular}

\section{miR-21 rs1292037 is Associated with T1DM}

Table 2 depicts detected genotypes as well as allele frequencies with their estimated ORs. In a codominant model, the T/C genotype was discovered significantly more frequent amongst T1DM patients $(32.4 \%)$ than amongst controls (14.8\%). In a dominant model, the frequency of the $\mathrm{T} / \mathrm{C}+\mathrm{C} / \mathrm{C}$ genotypes was significantly higher in the T1DM subjects (43.6\%) when compared to the controls (32\%). In a recessive model, the $\mathrm{T} / \mathrm{C}$ genotype was found to be significantly associated with the incidence of T1DM $(O R=2.74(1.78-4.27), P<0.0001)$. The minor $C$ allele was significantly more prevalent in patients than controls $(\mathrm{OR}=1.36(1.03-0.8), \mathrm{P}=0.02)$. 
Table 2

Genetics of miR-21 SNP in patients and controls

\begin{tabular}{|c|c|c|c|}
\hline \multirow[t]{2}{*}{ Model } & Patients & Controls & OR \\
\hline & $N(\%)$ & $N(\%)$ & (95\% Cl) \\
\hline \multicolumn{4}{|c|}{ Codominant genotype } \\
\hline$T / T$ & $141(56.4 \%)$ & $170(68 \%)$ & 1.00 \\
\hline $\mathrm{T} / \mathrm{C}$ & $81(32.4 \%)$ & $37(14.8 \%)$ & $2.63(1.68-4.13)^{a}$ \\
\hline $\mathrm{C} / \mathrm{C}$ & $28(11.2 \%)$ & $43(17.2 \%)$ & $0.78(0.46-1.32)^{\mathrm{b}}$ \\
\hline \multicolumn{4}{|c|}{ Dominant genotype } \\
\hline$T / T$ & $141(56.4 \%)$ & $170(68 \%)$ & 1.00 \\
\hline $\mathrm{T} / \mathrm{C}+\mathrm{C} / \mathrm{C}$ & $109(43.6 \%)$ & $80(32 \%)$ & $1.64(1.14-2.36)^{\mathrm{C}}$ \\
\hline \multicolumn{4}{|c|}{ Recessive genotype } \\
\hline $\mathrm{T} / \mathrm{T}+\mathrm{T} / \mathrm{C}$ & $222(88.8 \%)$ & $207(82.8 \%)$ & 1.00 \\
\hline $\mathrm{C} / \mathrm{C}$ & $28(11.2 \%)$ & $43(17.2 \%)$ & $0.6(0.36-1.01)^{d}$ \\
\hline \multicolumn{4}{|c|}{ Over-dominant genotype } \\
\hline $\mathrm{T} / \mathrm{T}+\mathrm{C} / \mathrm{C}$ & $169(67.6 \%)$ & $213(85.2 \%)$ & 1.00 \\
\hline $\mathrm{T} / \mathrm{C}$ & $81(32.4 \%)$ & $37(14.8 \%)$ & $2.74(1.78-4.27)^{a}$ \\
\hline \multicolumn{4}{|l|}{ Allele } \\
\hline $\mathrm{T}$ & $363(72.6 \%)$ & $377(75.4 \%)$ & 1.00 \\
\hline C & $137(27.4 \%)$ & $123(24.6 \%)$ & $1.36(1.03-1.8)^{\mathrm{e}}$ \\
\hline \multicolumn{4}{|c|}{${ }^{a} p<0.0001,{ }^{b} p=0.36,{ }^{c} p=0.007,{ }^{d} p=0.056,{ }^{e} p=0.02$. OR $=$ Odds ratio, $C l=$ Confidence interva } \\
\hline
\end{tabular}

Quantitative real-time PCR (qRT-PCR) was used to determine the relative expression of the miR-21 gene in the T1DM patient and control groups. The acquired data revealed a significant difference in the miR-21 expression level between T1DM patients and normal controls. As illustrated in Fig. 1, the mean expression level of miR-21 in the control subjects and T1DM patients was calculated to be 1 and 2.34, respectively. The results stipulate that the miR-21 gene is significantly increased in T1DM patients compared to the control group by nearly twofold $(p<0.0001)$. In the study population, those who carried the $\mathrm{T} / \mathrm{C}$ genotype were recognized to have a significantly higher miR-21 expression (Fig. 2). 


\section{3- Discussion}

miR-21 (rs1292037) SNP was determined in 250 T1DM patients and 250 population-matched controls. We report a significant association between the miR-21 rs1292037T/C genotype and the incidence of T1DM. It was also found that miR-21 is significantly overexpressed in T1DM patients comparing to the control group. Moreover, this study demonstrated that miR-21 was significantly upregulated in subjects with the $T / C$ genotype.

MiRNAs, as regulators of gene expression, are seen to contribute to several pathological conditions including T1DM (18). SNPs in the miRNAs coding gene are reported to affect the biological function of these non-coding RNAs, which can lead to the incidence of numerous human diseases (19). Multiple studies have investigated the role of miRNAs-relates SNPs in the incidence and prognosis of T1DM. For instance, miR-196a rs11614913 is reported to be associated with the pathogenesis of T1DM (13). Moreover, studies have shown that SNPs in miRNAs coding genes can determine the development of pancreatic cells and insulin secretion. For instance, Wang et al. have detected a link between miR-124a rs531564 and miR-27a rs895819, and pancreatic development, adipocyte differentiation, and insulin secretion (20). It is observed that miR-21 targets genes that act in cell proliferation and cell apoptosis including Ras and Pdcd4 (21). SNPs in the miRNA coding genes are seen to affect the binding affinity and binding ability of miRNAs, which can consequently affect the expression of the miRNA target genes (9). Although miR-21 rs1292037 is seen to be correlated with the prognosis of hepatocellular carcinoma and cervical cancer, there is no reported evidence on the association of this reference SNP and T1DM (14, 22).

In addition to the critical role of miR-SNPs in the incidence and prognosis of autoimmune diseases such as T1DM, alteration in the expression level of miRNAs in autoimmune diseases is manifested by several researchers (23). In a research conducted by Mostahfezian et al., it is reported that miR-21 is upregulated in T1DM patients. They postulated that upregulated levels of miR-21 inhibit T cells apoptosis, which leads to autoimmunity (17). Compelling evidence has shown that upregulation of miR-21 can expose $\beta$ cells to proinflammatory cytokines. This unfortunate phenomenon promotes cell death, which stimulates T1DM (24). Upregulation of miR-21 in T1DM patients is also reported by Fouad and their colleagues. Analyzing the plasma of T1DM patients, they tracked the upregulated levels of miR-21. Moreover, they claimed that in the first 5 years of the disease onset, when is even sooner than the development of microalbuminuria, upregulated levels of this miRNA can be detected (25).

Analyzing miRNAs expression level and/or miRNAs-related SNPs have been proposed as a biomarker in medicine and biotechnology for the early detection of diseases with genetic backgrounds $(26,27)$. Regarding T1DM, the early detection of this disease not only increases the quality of life in patients but also elevates the possibility of preventing T1DM complications such as heart disease, foot ulcer, retinopathy, and neuropathy (28). More importantly, early detection of T1DM can positively affect the honeymoon period (a transition remission phase after the commencement of insulin treatment that insulin doses can be significantly decreased or even totally withdrawn) (29). In this case, the specialists 
will be given more time to take considerable actions (e.g., adjunctive therapy) to prolong the reduction of residual $\beta$ cell function in T1DM patients (30). Taken together, the results of this study suggest that $m i R$ $21 \mathrm{rs} 1292037 \mathrm{~T} / \mathrm{C}$ genotype can be considered as a putative biomarker for early detection of T1DM. Moreover, analyzing miR-21 expression patterns can be also evaluated for this purpose.

Some limitations should be considered when the acquired data are analyzed. Firstly, this study included 250 T1DM patients and 250 control subjects, and therefore, expanded research with a larger case and control population is recommended. Secondly, this research was limited to the Iranian population, and the authors realize that there might be differences in this SNP in the T1DM characteristics of distinct populations. For this reason, we recommend further investigations into other ethnic/racial groups.

\section{4- Conclusions}

In conclusion, after genotyping 250 patients with T1DM and 250 control subjects, we discovered that miR-21 rs1292037T/C genotype is significantly linked to the incidence of T1DM. Additionally, we observed that miR-21 is significantly overexpressed in T1DM patients when compared to control subjects. We also report that the miR-21 level is seen to be significantly elevated in the study subjects who carried the $\mathrm{T} / \mathrm{C}$ genotype.

\section{5- Materials And Methods 5.1- Subjects}

We designed a case-control study involving 250 randomly-selected patients diagnosed with T1DM and 250 randomly-chosen healthy control subjects, from 17 Shahrivar hospital, Rasht, Iran. The peripheral venous blood from subjects was collected in EDTA-containing tubes. T1DM was diagnosed based on the criteria published by the American Diabetes Association in 2014 (31). Cases with at least 6 months of T1DM with concomitant insulin injection were included and patients with severe complications of T1DM such as nephropathy were excluded. All healthy individuals were interviewed in order to collect information regarding the clinical and biochemical characteristics of the study subjects. Control subjects with a history of autoimmune diseases and/or pathological findings were excluded. The two groups were age-matched: the mean [SD] for cases and controls are 10.26 [3.57] and 10.81 [3.58], respectively $(P=$ 0.112). The study was performed according to the principles of the 1964 Helsinki declaration and its further amendments.

\section{2- Methods}

\section{Genotyping}

The genomic DNA was extracted from peripheral blood samples of all study subjects using Triton X-100. The concentration and purity of the extracted DNA were evaluated by the NanoDrop spectrophotometer 
(Thermo Fisher Science, USA). Genotyping of rs 1292037 was achieved using polymerase chain reaction (PCR), followed by restriction fragment length polymorphism (RFLP). Forward and reverse primers of miR-21 rs 1292037 were 5'-ACTGTCTGCTTGTTTTGCCTA-3' and 5'- TGAAAGAGATGAACCACGACT-3', respectively. The PCR amplification was performed in a $20 \mu \mathrm{l}$ reaction volume consisting of $3 \mu \mathrm{l}$ of the extracted DNA (30 ng/ $\mu \mathrm{l}), 10 \mu \mathrm{l}$ of Taq DNA polymerase Master Mix Red (Ampliqon, Denmark), and $1 \mu \mathrm{l}$ $(10 \mathrm{pmol} / \mu \mathrm{l})$ of each primer (forwards and reverse). Samples were subjected to amplification in an MJ Mini thermocycler (BioRad, USA). The following PCR condition was employed for this purpose: an initial denaturation step at $94^{\circ} \mathrm{C}$ for $5 \mathrm{~min}$, amplification for 35 rounds at $94^{\circ} \mathrm{C}$ for $45 \mathrm{sec}, 57^{\circ} \mathrm{C}$ for $45 \mathrm{sec}$, and $72^{\circ} \mathrm{C}$ for $45 \mathrm{sec}$, followed by an elongation step at $72^{\circ} \mathrm{C}$ for $5 \mathrm{~min}$. The PCR products ( $540 \mathrm{bp}$ ) were then analyzed by $1 \%$ agarose gel electrophoresis in Tris-Boric acid-EDTA buffer and stained by RedSafe Nucleic Acid Staining Solution (Boca Scientific, USA). In order to detect allelic variations, the amplicons were digested by the TspRI restriction enzyme (Thermo Fisher Scientific, USA), according to the manufacturer's protocol. After digestion with TspRI, the PCR product was cut into $338 \mathrm{bp}$ and $202 \mathrm{bp}$ fragments in the presence of the $C$ allele whereas the $T$ allele remained uncut (540 bp). The enzymedigested products were then separated on $2 \%$ agarose gel and stained by RedSafe.

\section{RNA extraction and quantitative Real-Time PCR}

miRNAs were isolated from the peripheral blood using the SanPrep Column microRNA Mini-Prep Kit (Bio Basic, Canada) according to the manufacturer's instruction. RNA integrity was analyzed using $2 \%$ agarose gel electrophoresis. RNA purity was then assessed using a NanoDrop spectrophotometer.

The complementary DNA (CDNA) was synthesized using a RevertAid ${ }^{\text {TM }}$ First Strand cDNA Synthesis Kit (Thermo Fisher Scientific, USA) with a miR-21 stem-loop primer (5'-

GTCGTATCCAGTGCAGGGTCCGAGGTATTCGCACTGGATCAACA-3'), according to the manufacturer's guideline. This stem-loop primer was specifically designed for this study. The process then was followed by reverse transcription- PCR (RT-PCR).

qRT-PCR was performed to evaluate the expression level of miR-21 in T1DM patients and control subjects. Genotyping was performed in a $20 \mu \mathrm{l}$ reaction mixture consisting of $1 \mu \mathrm{l}$ of cDNA $(2 \mu \mathrm{g} / \mu \mathrm{l}), 10 \mu \mathrm{l}$ of SYBR-Green 2X Mastermix (TB Green Premix Ex Taq II Tli RNase H Plus; Takara, Japan), $1 \mu \mathrm{l}$ (5pmol/ $\mu l)$ of each specific forward and reverse primers. Amplification was performed using an MJ Mini Thermo Cycler (BioRad, USA). Cycling conditions were 5 min incubation at $95^{\circ} \mathrm{C}, 45$ cycles of $95^{\circ} \mathrm{C}$ for $30 \mathrm{sec}$, $63^{\circ} \mathrm{C}$ for $30 \mathrm{sec}$, and $72^{\circ} \mathrm{C}$ for $30 \mathrm{sec}$, followed by an extension time of $5 \mathrm{~min}$ at $72^{\circ} \mathrm{C}$. The $U 48$ was used as the endogenous control to normalize the expression value of miR-21. The used primers are as follows: miR-21 (F): 5'-GGTGTAGCTTATCAGACTGATG-3', miR-21 (R): 5'-AGGGTCCGAGGTATTCGC-3', U48 (F): 5'GAGTGATGATGACCCCAGGTAA-3', and U48 (R): 5'- GTGCAGGGTCCGAGGT-3'. All reactions were performed in triplicate. The fold changes in the expression level were calculated by the $2^{-\triangle \triangle C T}$ method (32).

\section{Statistical Analysis}


The chi-squared $\left(\chi^{2}\right)$ test was used to evaluate the differences in the genotype and allelic distribution between T1DM patients and healthy controls. The Hardy-Weinberg Equilibrium (HWE) was assessed by a goodness-of-fit $\chi^{2}$ test. To investigate the strength of association, odds ratios (ORs) with $95 \%$ confidence intervals (Cls) were used. P-values less than 0.05 were considered statistically significant. SNP genotyping-related data were analyzed using MedCalc statistical software (version 19.5.3; Belgium). All other data and information were analyzed and studied using Graphpad Prism (version 8.0.2, USA).

\section{List Of Abbriviations}

T1DM: Type 1 diabetes mellitus

miRNAs: microRNAs

3'UTR: 3' untranslated region

SNPs: Single-nucleotide polymorphisms

PCR: Polymerase chain reaction

qRT-PCR: Quantitative real-time PCR

ORs: Odds ratios

Cls: Confidence intervals

\section{Declarations}

\section{Ethics approval and consent to participate}

All subjects, both patients and controls, signed written informed consent after receiving an extensive disclosure of the purpose of the study. The study was approved by the responsible ethical committee of Guilan University of Medical Sciences (Approval ID: IR.GUMS.REC.1397.427).

\section{Consent for publication}

Not applicable.

\section{Availability of data and materials}

The datasets used and/or analyzed during the current study are available from the corresponding authors on reasonable request.

\section{Competing interest}

The authors declare no potential conflict of interest. 


\section{Funding}

The authors did not receive financial support for any part of this article.

\section{Authors contribution}

Reza Bayat contributed to the laboratory work and drafted the manuscript. Zivar Salehi defined the study protocol, drafted the manuscript, and supervised the whole project. Setila Dalili defined the study protocol and drafted the manuscript. Farbod Bahreini provided the final revision of the manuscript, and was in charge of the submission process. All the authors have given the final approval of the version to be published and they take responsibility for appropriate portions of the content.

\section{Acknowledgments}

The authors would like to thank all the T1DM patients and healthy volunteers who willingly participated in this study.

The authors also acknowledge the support of the University of Guilan.

\section{References}

1. Bachle C, Icks A, Strassburger K, Flechtner-Mors M, Hungele A, Beyer P, et al. Direct diabetes-related costs in young patients with early-onset, long-lasting type 1 diabetes. PLoS One. 2013;8(8):e70567.

2. Pang H, Luo S, Huang G, Xia Y, Xie Z, Zhou Z. Advances in knowledge of candidate genes acting at the beta-cell level in the pathogenesis of T1DM. Frontiers in Endocrinology. 2020;11.

3. Katsarou A, Gudbjörnsdottir S, Rawshani A, Dabelea D, Bonifacio E, Anderson BJ, et al. Type 1 diabetes mellitus. Nature reviews Disease primers. 2017;3(1):1-17.

4. Pociot F, McDermott M. Genetics of type 1 diabetes mellitus. Genes \& Immunity. 2002;3(5):235-49.

5. Saeedi P, Petersohn I, Salpea P, Malanda B, Karuranga S, Unwin N, et al. Global and regional diabetes prevalence estimates for 2019 and projections for 2030 and 2045: Results from the International Diabetes Federation Diabetes Atlas. Diabetes research and clinical practice. 2019;157:107843.

6. Cooke DW, Plotnick L. Type 1 diabetes mellitus in pediatrics. pediatr Rev. 2008;29(11):374-84.

7. Aguayo-Mazzucato $C$, Bonner-Weir S. Pancreatic $\beta$ cell regeneration as a possible therapy for diabetes. Cell metabolism. 2018;27(1):57-67.

8. Voltarelli JC, Couri CEB. Stem cell transplantation for type 1 diabetes mellitus. Diabetology \& metabolic syndrome. 2009;1(1):1-4.

9. Bahreini F, Rayzan E, Rezaei N. microRNA-related single-nucleotide polymorphisms and breast cancer. Journal of Cellular Physiology. 2020.

10. Guay C, Jacovetti C, Nesca V, Motterle A, Tugay K, Regazzi R. Emerging roles of non-coding RNAs in pancreatic $\beta$-cell function and dysfunction. Diabetes, Obesity and Metabolism. 2012;14:12-21. 
11. Bahreini F, Ramezani S, Shahangian S, Salehi Z, Mashayekhi F. miR-559 polymorphism rs58450758 is linked to breast cancer. British journal of biomedical science. 2020;77(1):29-34.

12. Mashayekhi S, Saeidi Saedi H, Salehi Z, Soltanipour S, Mirzajani E. Effects of miR-27a, miR-196a2 and miR-146a polymorphisms on the risk of breast cancer. Br J Biomed Sci. 2018;75(2):76-81.

13. Ibrahim AA, Ramadan A, Wahby AA, Hassan M, Soliman HM, Abdel Hamid TA. Micro-RNA 196a2 expression and miR-196a2 (rs11614913) polymorphism in T1DM: a pilot study. J Pediatr Endocrinol Metab. 2019;32(10):1171-9.

14. Zhang J, Li Y-H, Liu H-L, Zhang Y, Zhang Q-S, Li S-Z. Correlations of MicroRNA-21 gene polymorphisms with chemosensitivity and prognosis of cervical cancer. The American journal of the medical sciences. 2018;356(6):544-51.

15. Chacon-Cortes D, Smith RA, Haupt LM, Lea RA, Youl PH, Griffiths LR. Genetic association analysis of miRNA SNPs implicates MIR145 in breast cancer susceptibility. BMC Medical Genetics. 2015;16(1):111.

16. Xiang Y, Guo J, Peng Y-F, Tan T, Huang H-T, Luo H-C, et al. Association of miR-21, miR-126 and miR605 gene polymorphisms with ischemic stroke risk. Oncotarget. 2017;8(56):95755.

17. Mostahfezian M, Azhir Z, Dehghanian F, Hojati Z. Expression Pattern of microRNAs, miR-21, miR-155 and miR-338 in Patients with Type 1 Diabetes. Arch Med Res. 2019;50(3):79-85.

18. Tian J, Pan W, Xu X, Tian X, Zhang M, Hu Q. NF-kB inhibits the occurrence of type 1 diabetes through microRNA-150-dependent PUMA degradation. Life sciences. 2020;255:117724.

19. Rong G, Zhu Y, Tang W, Qiu H, Zhang S. The correlation of microRNA-499 rs3746444 T>C locus with the susceptibility of gastric cancer: from a case-control study to a meta-analysis. Bioscience Reports. 2021;41(1).

20. Wang T-T, Chen Y-J, Sun L-L, Zhang S-J, Zhou Z-Y, Qiao H. Affection of single-nucleotide polymorphisms in miR-27a, miR-124a, and miR-146a on susceptibility to type 2 diabetes mellitus in Chinese Han people. Chinese medical journal. 2015;128(4):533.

21. Bahreini F, Rayzan E, Rezaei N. MicroRNAs and Diabetes Mellitus Type 1. Current Diabetes Reviews. 2021.

22. Wu C, Tang G, Wang X, Zhang J, Chen S, Lu C, et al. Micro-RNA-21 rs1292037 A> G polymorphism can predict hepatocellular carcinoma prognosis (HCC), and plays a key role in cell proliferation and ischemia-reperfusion injury (IRI) in HCC cell model of IRI. Saudi medical journal. 2020;41(4):383-93.

23. Miao C, Chang J, Zhang G, Fang Y. MicroRNAs in type 1 diabetes: new research progress and potential directions. Biochemistry and Cell Biology. 2018;96(5):498-506.

24. Backe MB, Novotny GW, Christensen DP, Grunnet LG, Mandrup-Poulsen T. Altering $\beta$-cell number through stable alteration of miR-21 and miR-34a expression. Islets. 2014;6(1):e27754.

25. Fouad M, Salem I, Elhefnawy K, Raafat N, Faisal A. MicroRNA-21 as an early marker of nephropathy in patients with type 1 diabetes. Indian journal of nephrology. 2020;30(1):21. 
26. Ganepola GA, Rutledge JR, Suman P, Yiengpruksawan A, Chang DH. Novel blood-based microRNA biomarker panel for early diagnosis of pancreatic cancer. World journal of gastrointestinal oncology. 2014;6(1):22.

27. Salzman DW, Weidhaas JB. SNPing cancer in the bud: microRNA and microRNA-target site polymorphisms as diagnostic and prognostic biomarkers in cancer. Pharmacology \& therapeutics. 2013;137(1):55-63.

28. Nik Mohamed Kamal NNSB, Shahidan WNS. Non-exosomal and exosomal circulatory microRNAs: Which are more valid as biomarkers? Frontiers in pharmacology. 2020;10:1500.

29. Van Belle TL, Coppieters KT, Von Herrath MG. Type 1 diabetes: etiology, immunology, and therapeutic strategies. Physiological reviews. 2011;91(1):79-118.

30. Gabbay MA, Sato MN, Finazzo C, Duarte AJ, Dib SA. Effect of cholecalciferol as adjunctive therapy with insulin on protective immunologic profile and decline of residual $\beta$-cell function in new-onset type 1 diabetes mellitus. Archives of pediatrics \& adolescent medicine. 2012;166(7):601-7.

31. Association AD. Diagnosis and classification of diabetes mellitus. Diabetes care. 2014;37(Supplement 1):S81-S90.

32. Livak KJ, Schmittgen TD. Analysis of relative gene expression data using real-time quantitative PCR and the 2(-Delta Delta C(T)) Method. Methods. 2001;25(4):402-8.

\section{Figures}




\section{Relative Expression of miR-21}

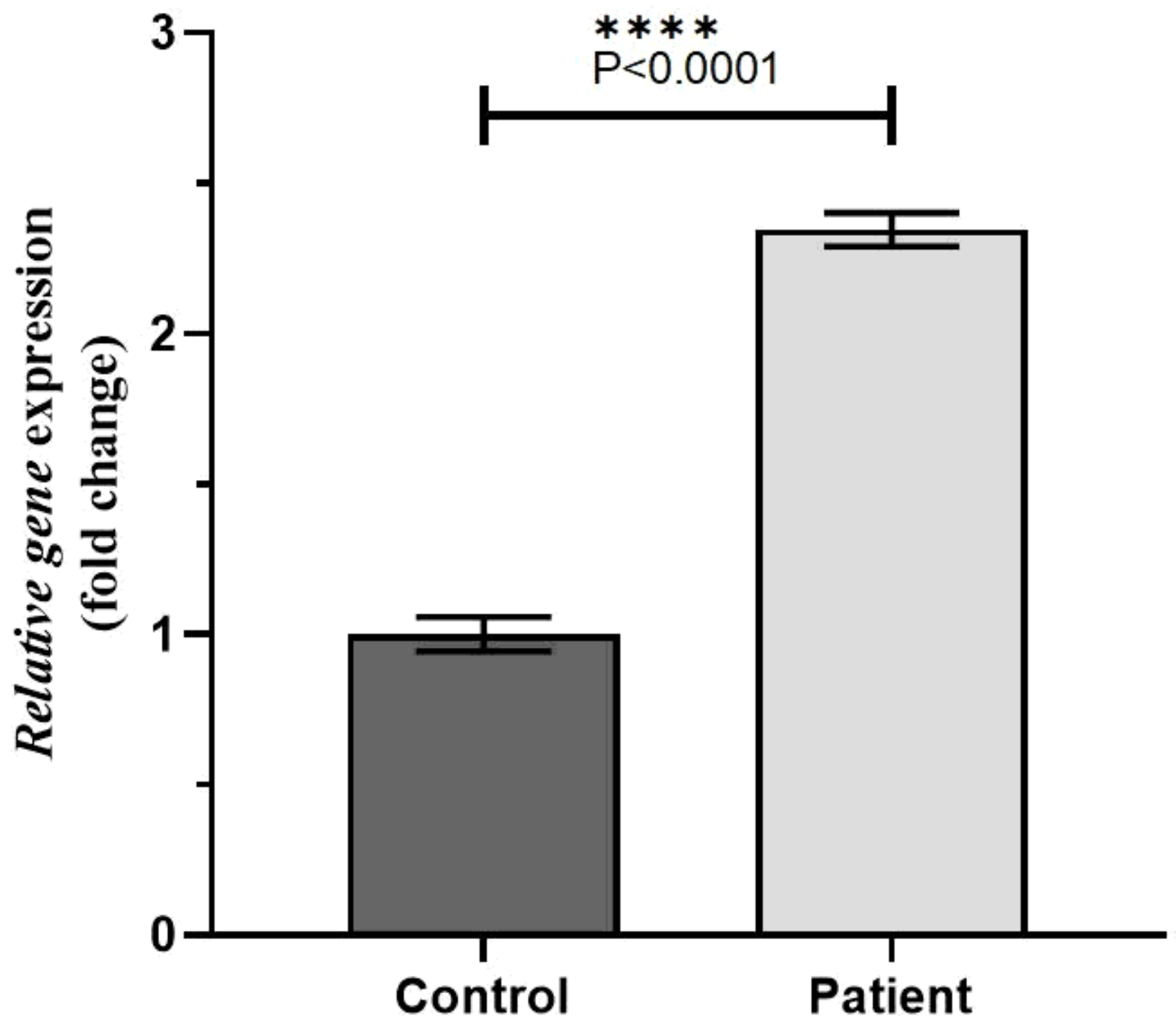

Figure 1

Relative gene expression of miR-21 in control subjects and T1DM patients. miR-21 is significantly upregulated in patients. 


\section{Relative Expression of miR-21}

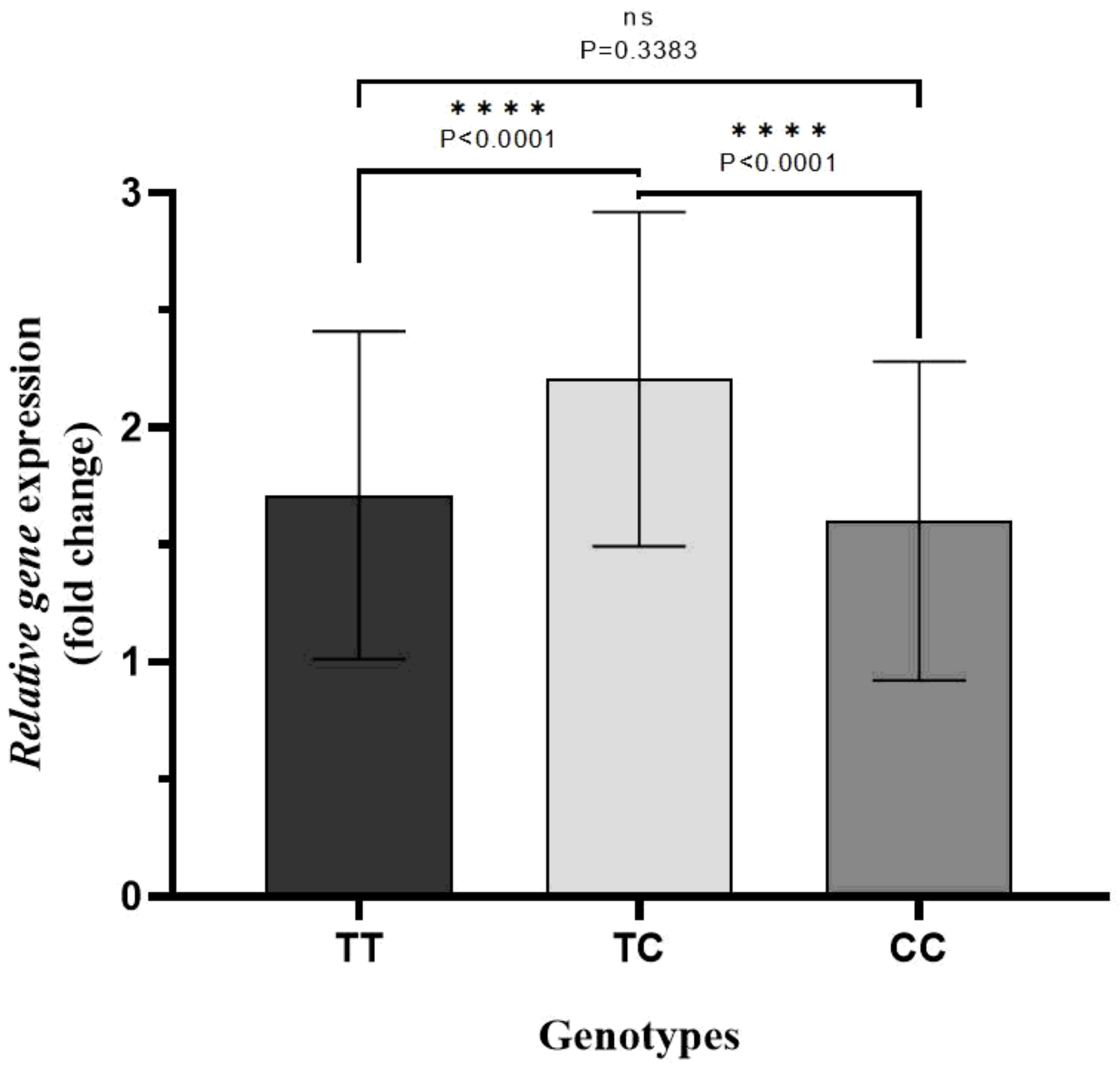

Figure 2

Relative gene expression of miR-21 in subjects carrying the T/T, T/C, or C/C genotypes. As illustrated, subjects with the $\mathrm{T} / \mathrm{C}$ genotype have the highest significant miR-21 expression. 